\title{
Communication of brands on social sites during the COVID-19 pandemic in the context of globalization
}

\author{
Martin Vanko ${ }^{1}$, Anna Zaušková ${ }^{1}$, Michal Kubovics ${ }^{1, *}$ \\ ${ }^{1}$ University of Ss. Cyril and Methodius in Trnava, Faculty of Mass Media Communication, Nam. J. \\ Herdu 2, Trnava 917 01, Slovak republic
}

\begin{abstract}
.
Research background: The global coronavirus crisis has become a household name across all segments of digital marketing communication. Whereas some brands primarily focused their communication on corporate social responsibility at that time (from March to May 2020). What and how the brands were communicated on social sites within the pandemic marketing communication can become a significant finding for the research into CSR or changes of digital behaviour of certain brands.

Purpose of the article: The purpose of the paper is to analyse and subsequently compare the content of a relevant brand to be published on Facebook in the context of globalization and during the first COVID-19 outbreak. In the paper, the authors dealt with the McDonald's and their communication and content to be published on Facebook within a specific time period (March to May 2020) in particular markets.

Methods: The authors intended to analyse content and format papers that were published and subsequently analysed - content or format consistency is the essence of social sites communication. The quantitative part will consist of the content analysis of key words and at the same time, the size and economic power of the target audience and their reactions will be observed. The qualitative part will entail evaluation of communication, content and current communication.

Findings \& Value added: There is a question if and what a relevant brand communicated to their consumers and fans on social sites during the COVID-19 outbreak or the state of emergency, as being responsible and staying home was the most effective vaccine against the COVID-19 pandemic.
\end{abstract}

Keywords: globalization; communication strategy; content strategy in the coronavirus crisis; social media strategy in COVID-19; social networks

JEL Classification: $M 30 ; M 31$

* Corresponding author: michal.kubovics@student.ucm.sk 


\section{Introduction}

The ongoing coronavirus pandemic has brought uncertainty as well as many challenges not only for the whole society but also for many businesses in the market environment. Whereas some businesses have started to reduce their marketing and advertising budgets, the others have used it as an opportunity how to get closer to their customers and consumers when they felt that need. R. A. Fattah and F. K. Sujono declare that communication on social sites has undergone dramatic changes, yet they emphasise certain freedom of communication regardless of any geographical factors [1]. In their paper, the authors focus on one of the biggest fast food chains in the world - McDonald's and its communication on Facebook during the first COVID-19 outbreak in the context of globalization. The authors aimed at defining any possible heterogeneity or consistency of McDonald's communication on social sites from March 1, 2020 until May 31, 2020. The presented analysis of the published content tends to define a proportion of globalization of one business entity operating across various markets. The authors focus on Facebook communication of the selected brand in the markets across the USA, Australia and Europe - especially in Slovakia. During the first outbreak, social sites became a platform for various free-time activities worldwide. This is also confirmed by L. Li et al., who speak about the users' need to obtain and exchange various pieces of information about COVID-19 in order to get ready for the situation [2]. The prognoses from the USA also report a higher rate of use of social sites, which is confirmed by the research published on statista.com, where the respondents were inquired whether they thought that the time they spent online had increased during the pandemic. In case of YouTube, Facebook and Instagram, the majority of respondents answered positively. As shown in the Picture 1 - up to $63.7 \%$ of respondents said they had been more active on YouTube, followed by $62.3 \%$ for Facebook and $43.1 \%$ for Instagram.

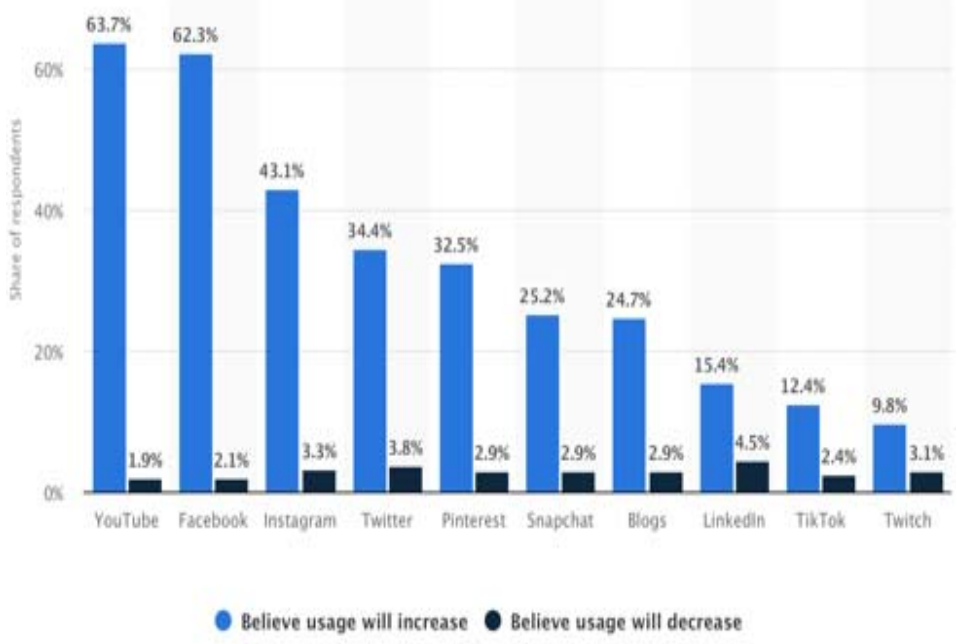

Fig. 1. Share of social media users in the United States who believe they will use select social media more if confined at home due to the coronavirus as of March 2020, by statista.com https://www.statista.com/statistics/1106343/social-usage-increase-due-to-coronavirus-home-usa/, 2020 
According to the research, we may state that the first pandemic outbreak triggered a higher activity of individuals on social networking sites and for this reason, we may assume that communication of brands, entities or various corporations on social sites was not only needed, but also expected. As N. Jail and M. Laroche put it, data obtained through social networking sites are a precious source of support of any other marketing activities of specific business entities - however, these data need to be properly analysed [3]. F. Xing et al. add that in case brands do not stop communicate with their fans under any circumstances, building brand loyalty will be continuous and natural and will result in higher sales [4]. We can only agree with it because this is to say that brands and businesses may obtain important and necessary feedback that may either positively or negatively affect their leadership. In light of the above mentioned, the authors of the paper decided to focus on one of the most successful restaurants in the world - McDonald's and its communication during the pandemic in the context of globalization. In the tables and graphs set out below, the authors demonstrate social responsibility or not of a selected subject reflecting on the natural continuity in communication and promotion of specific products or services which are offered by that subject during the lockdown as well as in the period of easing of measures against the spread of COVID-19.

In the year 2020, the social site Facebook (notably during the coronavirus crisis) has not only been described as a trend setter, but also as a modern as well as a traditional form of marketing communication. J. B. Ford defined Facebook as the users' first contact in the online space in the field of social networking sites or social media [5]. W. Tafesse and A. Wien agree with the above opinion while adding that certain performance of social sites has a direct and positive impact on the overall performance of marketing or any other proper marketing strategy [6]. The importance of social networking sites, primarily Facebook, has started to grow with the first coronavirus outbreak, although not exactly in the context of leisure time activities of social media followers. To many users, Facebook has become a core communication tool which has enabled them to stay safe at home and still be in touch with the outside world, friends, family, relatives, favourite brands or companies. A. Mastur et al. describe Facebook as a social networking site thanks to which consumers are able to be in touch with particular brands or companies and at the same time have greater control over purchase of products or services [7]. M. Losekoot assumes there are two main reasons behind the use of social networking sites: "Either they need to solve a problem or have fun. If you are looking for a new washing machine, a flat, love or a puppy, the Internet is able to deliver you all of these in a couple of hours" [8]. We agree with the above mentioned statements, but it needs to be said that in case social media users want to have fun - they can do so within a second. J. Jacobson studies social networking sites in the context of both the private and public sector - as for the private sector, it is a unique tool for promotion or sale of products and services and in the public sector, it serves as a tool for sharing information or promoting interactivity with specific users [9]. M. Losekoot, on the other hand, answers the question why users spend their free time on social sites: they want to be in the picture, which is understandable under the current circumstances caused by the coronavirus crisis; thanks to social sites, they are able to create a picture about themselves (in the first outbreak, many users were curious to know how their friends and relatives spend their free time at the time when the whole world went online) and build their own community or enhance their awareness [8]. Therefore, social sites can be considered so-called "business imperative" because their content is happening in a real time and is transferred from the static and oneway sending of messages into a viral form through recommendations from friends and relatives [10]. Due to the fact that the emphasis of the whole population is placed on the online environment, brands and businesses need to be ready for that, should properly fulfil needs of particular users and at the same time, demonstrate a certain share of social 
responsibility through their communication on social sites, which is crucial for the society these days.

Despite the fact that Hausmann speaks about social networking sites as about a explicitly cheap tool for promotion [11] and C. Drummond, T. O'Toole and H. McGrath see the potential contribution of social sites in their low costs and simpler implementation in contrast to traditional marketing communication [12] - we cannot agree with these statements based upon the current tendency of businesses to cut their costs for marketing or social sites communication. If social sites were not a financially affordable tool for promoting a service or a product, businesses would certainly not reduce the budgets they had allocated therefor. Targeting users on Facebook is not possible without investments and creating content (either an idea or graphic) is an element that needs to be properly examined when setting a marketing strategy on social sites in the context of a company budget. M. Canovi and F. Pucciarelli also argue that corporations in the market environment recognise social or emotional advantages of their communication on social sites yet they are not able to use this potential due to a lack of finance, time consumption or huge investments into proper administration of social sites [13]. For this reason, we have decided to focus our writing on one of the most successful fast food chains in the world as we may assume that despite any possible reduction of the budget allocated for advertising or social sites, it is obvious that the company fully understands the importance of properly allocated investments in communication on Facebook or social sites in general.

\section{Methodology}

The presented paper Communication of brands on social sites during the COVID-19 pandemic in the context of globalization, as its name suggests, specifies communication of the selected company, McDonald's fast-food chain, on social site Facebook in the specific time from March 1, 2020 (the start of the first coronavirus outbreak) until May 30, 2020 when certain restrictions eased across the world. In the first part of the article, the authors work with secondary sources - statistics from the worldwide-known web site statista.com while in the second part they rely on primary data incorporated into the analysis of Facebook posts reflecting the company communication in three different markets - USA, Australia and Europe (Slovakia). Within the given content analysis we focused on evaluation and interpretation of the content the company published on Facebook in the given time period. Within this analysis, we emphasised the use of available formats for communication on social sites, namely specific content that helped us analyse particular posts from the point of view of their timeliness, authenticity or description of the current situation in the context of coronavirus pandemic. The only global Facebook page of McDonald's was used for the analysis: https://www.facebook.com/mcdonalds.sk/ with 80,576,835 fans and 80,576,012 followers (September 2020) despite the fact that the content analysis uses posts from the American, Australian and Slovak McDonald's franchises. Global Facebook pages use geo targeting of the content as the users' individual location is used for their targeting [14]. According to the advertising agency Triad, the greatest benefits of these global pages are as follows: the only one centralised page with consistent brand identity - the same name is used worldwide even in a local language, then unified global statistics and one URL address directing you to a local webpage [15].

When evaluating the presented content analysis, the authors work with statistical description where the data are transcribed into corresponding graphs and tables. Posts are categorised in specific tables according to the date of publishing, format, content, interaction, the number of comments and sharing for each individual market (USA, Australia, Slovakia) and what is more, they are divided according to their content orientation into communication of the pre-determined agenda (products, services, free time) and communication of the 
COVID-19-related content. The graphs in the second part of the article observe the ratio of the format composition of particular posts in each country that was subject of the research. In the final part, the authors draw conclusions and connections between the format and content division of the published content within the countries or between one another. The outcome of the content analysis is to determine certain globalization in the context of communication of the selected company on social sites during the coronavirus pandemic.

\section{Results}

In their content analysis, the authors of the paper focus on McDonald's communication philosophy on social sites during the first coronavirus outbreak from March 1, 2020 until May 30, 2020. The tables set out below present the evaluated data that had been obtained by observation, description and content analysis on the McDonald's global Facebook page across the markets in the USA, Australia and Europe, especially in Slovakia. As shown in the tables, the data present three the most successful posts from the point of view of their interactions, comments and sharing which are categorised into the posts about the company everyday agenda (sale of products, services, free time activities) and those concerning the coronavirus pandemic. In the last part of the paper, the authors draw particular conclusions and connections between the formats and contents having been published on specific markets where McDonald's is operating in the context of globalization and the success rate of the analysed stories.

Facebook stories published in the US market were the first ones to have been analysed. In course of three months (March to May 2020), the US McDonald's posted 18 stories out of which almost a half (61.11\%) were directly linked to COVID-19 while the rest $(38.89 \%)$ promoted products, services or focused on various free-time activities of Facebook fans or followers. Table 1 shows three the most successful posts having no connection with the COVID-19 topic whatsoever. The most successful one as for the number of interactions, comments and sharing was the post from April 1, 2020 which was described as the static picture as for its format and the generated content from Twitter shared on Facebook as for its content.

Table 1. The most successful posts published on Facebook by the American company McDonald's during March-May 2020 apart from the COVID-19 topic

\begin{tabular}{|c|c|c|c|c|c|}
\hline Date & Format & Content & Interaction & Comments & Sharing \\
\hline April 1, 2020 & $\begin{array}{c}\text { Static } \\
\text { picture }\end{array}$ & $\begin{array}{c}\text { UGC content shared from } \\
\text { Twitter }\end{array}$ & 7,100 & 1,400 & 836 \\
\hline April 15, 2020 & $\begin{array}{c}\text { Static } \\
\text { picture }\end{array}$ & $\begin{array}{c}\text { UGC content shared from } \\
\text { Twitter }\end{array}$ & 1,100 & 875 & 195 \\
\hline April 16,2020 & Video & $\begin{array}{c}\text { Promotion of 24-hour } \\
\text { opening }\end{array}$ & 1,600 & 941 & 765 \\
\hline
\end{tabular}

Table 2 shows the posts having a direct connection to the coronavirus outbreak, out of which the most successful one as for the number of interactions, comments and sharing was the post dated March 25, 2020 when the US franchise promoted a take-away service with free delivery through a call for action button - thus demonstrating its social engagement in preventing the spread of the disease with a special added value for its customers - free delivery. The infographic posted on March 17, 2020 reported the highest proportion of sharing (10.200) where the company management published their official statement on the 
situation and emphasised the need to respect all the hygienic measures and regulations, which fans highly acclaimed as a sign of corporate social responsibility.

Table 2. The most successful posts published on Facebook by the American company McDonald's during March-May 2020 about the COVID-19 topic

\begin{tabular}{|c|c|c|c|c|c|}
\hline Date & Format & Content & Interaction & Comments & Sharing \\
\hline March 17, 2020 & Infografic & $\begin{array}{c}\text { Management } \\
\text { statement on the } \\
\text { current situation }\end{array}$ & 13,400 & 3,100 & 10,200 \\
\hline March 25, 2020 & $\begin{array}{c}\text { Animation with } \\
\text { a call to action } \\
\text { button }\end{array}$ & $\begin{array}{c}\text { Take-away } \\
\text { promotion for 0 \$ }\end{array}$ & 15,800 & 3,200 & 2,900 \\
\hline May 7, 2020 & Animation & $\begin{array}{c}\text { Distributing the food } \\
\text { to people in the first } \\
\text { line }\end{array}$ & 10,700 & 1,800 & 3,800 \\
\hline
\end{tabular}

In the context of the rate of use of all available formats for communication on social sites, Figure 2 shows that a static image was the most frequently used format of the US company (35.29\%) followed by a creative animation $(29,41 \%)$ and an infographic combining the text and the picture that was created in a graphic programme $(23.53 \%)$ while a video seemed to be the least frequently used format of the American McDonald's during the first outbreak.

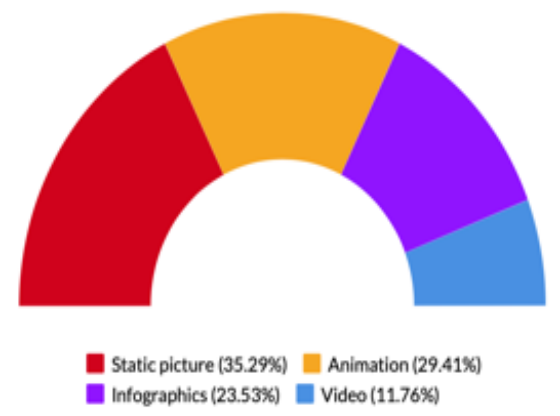

Fig. 2. Rate of use of formats on social sites by the American company McDonald's

Afterwards, we analysed the posts to have been published by McDonald's in the Australian market. In the given period, the company posted 15 stories which were almost identically divided into the category of ordinary promotion of products, services and freetime activities (53.33\%) and those concerning the coronavirus pandemic (46.67\%). Table 3 shows the selection of the most successful posts by the Australian McDonald's from the point of view of their interactions, comments and sharing in each particular category - the posts concerning promotion of products, services and free time activities and the posts relating to coronavirus. As for its interactions $(2,700)$, comments $(3,700)$ and sharing $(1,100)$, the post dated April 1, 2020 about a breakfast menu was the most successful story. 
Table 3. The most successful posts published on Facebook by the Australian company McDonald's during March-May 2020 apart from the COVID-19 topic

\begin{tabular}{|c|c|c|c|c|c|}
\hline Date & Format & Content & Interaction & Comments & Sharing \\
\hline April 1, 2020 & Animation & $\begin{array}{c}\text { Breakfast } \\
\text { menu } \\
\text { promotion }\end{array}$ & 2,700 & 3,700 & 1,100 \\
\hline April 8, 2020 & Animation & $\begin{array}{c}\text { Easter and } \\
\text { McDrive }\end{array}$ & 400 & 1,600 & 41 \\
\hline May 8, 2020 & Video & Mother's Day & 1,700 & 561 & 227 \\
\hline
\end{tabular}

As demonstrated in Table 4 showing three the most successful posts about COVID-19, it may be said that as for their interactions $(3,300)$, comments $(1,600)$ and sharing $(988)$, the most successful post was the static picture with a call for action button promoting the availability of products through delivery or drive-in, thus helping to prevent the spread of the virus.

Table 4. The most successful posts published on Facebook by the Australian company McDonald's during March-May 2020 about the COVID-19 topic

\begin{tabular}{|c|c|c|c|c|c|}
\hline Date & Format & Content & Interaction & Comments & Sharing \\
\hline March 16, 2020 & Text & $\begin{array}{c}\text { Management } \\
\text { statement on the } \\
\text { current situation }\end{array}$ & 2,500 & 1,300 & 328 \\
\hline March 20, 2020 & Animation & $\begin{array}{c}\text { Promotion of } \\
\text { contactless payments }\end{array}$ & 1,500 & 587 & 206 \\
\hline May 7, 2020 & $\begin{array}{c}\text { Static picture } \\
\text { with a call to } \\
\text { action button }\end{array}$ & $\begin{array}{c}\text { Take-away and } \\
\text { McDrive promotion }\end{array}$ & 3,300 & 1,600 & 988 \\
\hline
\end{tabular}

As for the types of formats available on Facebook and in contrast to the USA, an animation $(53.33 \%)$, a static picture $(26.67 \%)$, a video $(13.33 \%)$ and a simple text form (6.67\%) have become the most frequently used formats in Australia. Despite the fact that in our marketing practice a text form is not regarded as highly professional, we have decided to place it among the most successful formats. We may also assume that during the pandemic the users are not particularly interested in the format or communication of a given piece of information - they would rather prioritise its value or social responsibility.

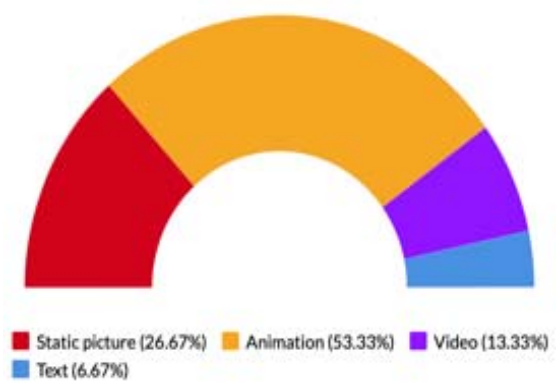

Fig. 3. Rate of use of formats on social sites by the Australian company McDonald's 
The posts published on Facebook by the Slovak McDonald's were the last ones to have been analysed. As for the number of posts, this is the market where the highest proportion of posts were published from March 1, 2020 and May 30, 2020 - 60. More than a half of them $(53.33 \%)$ were directly linked to coronavirus while the rest $(46.67 \%)$ dealt with promotion of products, services or free-time activities. Table 5 also demonstrates three the most successful posts of the Slovak McDonald's in the category of products, services and free times activities - the infographic about the Mother's Day, also promoted across the USA or Australia, was predominant as for the number of interactions $(1,100)$ while the infographic about the birthday party competition was the winner as for the number of comments (130) and sharing (71).

Table 5. The most successful posts published on Facebook by the Slovak company McDonald's during March-May 2020 apart from the COVID-19 topic

\begin{tabular}{|c|c|c|c|c|c|}
\hline Date & Format & Content & Interaction & Comments & Sharing \\
\hline March 8, 2020 & Infographic & Mother's Day & 1,100 & 58 & 6 \\
\hline April 20, 2020 & Infographic & $\begin{array}{c}\text { Birthday Party } \\
\text { Competition }\end{array}$ & 819 & 130 & 71 \\
\hline May 17, 2020 & $\begin{array}{c}\text { Static } \\
\text { picture }\end{array}$ & $\begin{array}{c}\text { Product } \\
\text { Promotion }\end{array}$ & 805 & 74 & 2 \\
\hline
\end{tabular}

Table 6 shows the success rate of posts to have been published by McDonald's in the Slovak market in the field of coronavirus pandemic. As for its interactions (549), the most successful post was the static photo of a change of a company profile photo from March 18, 2020 - when the company added a face mask to its traditional logo to show its fans that responsibility and wearing a face mask are the most effective vaccines against the spread of the disease. As for the number of comments (67) and sharing (165), the most successful post was the video the Slovak McDonald's published within its campaign called Bed Time Stories where the company published bed time stories for kids who had to stay at home because of the lockdown. We may therefore assume that customers highly acclaimed the company social responsibility as well as its prompt reaction to current issues within the society and helped the youth fill the time they had to spend at home.

Table 6. The most successful posts published on Facebook by the Slovak company McDonald's during March-May 2020 about the COVID-19 topic

\begin{tabular}{|c|c|c|c|c|c|}
\hline Date & Format & Content & Interaction & Comments & Sharing \\
\hline March 18, 2020 & $\begin{array}{c}\text { Static } \\
\text { picture }\end{array}$ & $\begin{array}{c}\text { Changing a profile photo } \\
\text { into a logo with a face } \\
\text { mask }\end{array}$ & 549 & 33 & 19 \\
\hline March 23, 2020 & Infographic & $\begin{array}{c}\text { Coffee for free for the } \\
\text { people in the first line }\end{array}$ & 329 & 22 & 33 \\
\hline April 6, 2020 & Video & $\begin{array}{c}\text { Bed time stories - content } \\
\text { for kids who had to stay } \\
\text { home }\end{array}$ & 309 & 67 & 165 \\
\hline
\end{tabular}

A static photo (46.67\%) was the most popular format to have been used in the Slovak market, followed by an infographic $(31.67 \%)$, videos $(11.67 \%)$, animations $(6.67 \%)$ and the 
format that was not used by the company in both the USA and Australia - a web link to a third party's webpage (3.33\%).

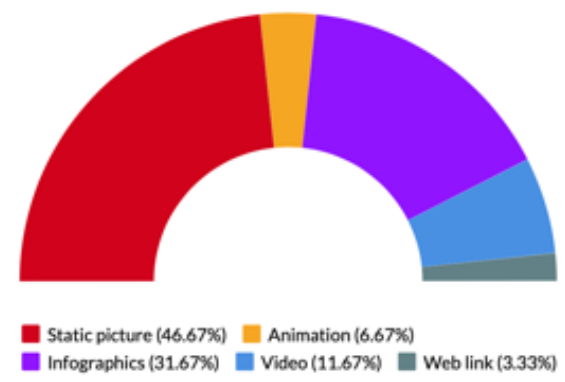

Fig. 4. Rate of use of formats on social sites by the Slovak company McDonald's

Based upon the results of the content analysis mentioned above, it may be said that the selected company maintained certain consistency in its communication on social sites during the first coronavirus outbreak - especially in respect of posts concerning the company everyday agenda and those dealing with the coronavirus topic. In all the markets we analysed (USA, Australia, Slovakia), we observed a categoric division of the published posts. As for the format of a communicated message, we might have been surprised to observe a lower rate of use of videos in McDonald's Facebook communication. Marketing specialists from the Association of Digital Marketing Agencies declare that a video should be a key communication pillar on social networking sites because Internet users tend to prefer this form of content.[16] Based upon our practice, we may suggest that a reduced budget for advertising and marketing activities and costs optimising were the main reasons behind the absence of video content on Facebook. Creation of infographics, animations or static pictures seems to be much less expensive and therefore more preferable among the promoters.

\section{Conclusion}

In the last two years, Facebook has certainly been regarded as a key tool for digital marketing communication and due to the coronavirus outbreak, it has started to play an indispensable role in the online space. Our statements are supported by the content analysis presented in the paper which deals with communication of this brand on social networking sites during the first COVID-19 outbreak. The collected data that are presented in the third part of the paper have clearly demonstrated social responsibility of the company which did not only focus on its products and services but tried to fill free time of their fans and customers during the pandemic times while attempting to improve the company image. According to the followers, the most valuable activity was distribution of free food for more than 10 million workers in the first line in the USA or coffee for free for workers in the first line in Slovakia. At the time of the crisis or long-term social depression caused by various restrictions or limitations, it is necessary for brands to adapt their tone of voice to specific communication on social sites and at the same time, boost interactivity and mutual loyalty by regularly reacting to feedback of their customers who have suddenly turned into fans / non-consumers.

The contribution is a part of research project VEGA 1/0708/18 named: „Aspects of use of the SoLoMo marketing concept to enhance awareness of eco-innovations". 


\section{References}

1. Fattah, R.A., Sujono, F.K. (2020). Social presence of ruangguru in social media during covid-19 pandemic. Jurnal The Messenger, 12(2), 180.

2. Li, L., Zhang, Q., Wang, X., Zhang, J., Wang, T., Gao, T.-L., Duan, W., Tsoi, K. K., Wang, F.-Y. (2020). Characterizing the propagation of situational information in social media during covid-19 epidemic: A case study on weibo. IEEE Transactions on Computational Social Systems, 7(2), 556-562.

3. Hajli, N., Laroche, M. (2019). Applications of business intelligence and analytics in social media marketing. International Journal of Information Management, 48, 226227.

4. Xing, F., Poria, S., Cambria, E., Welsch, R. (2020). Social media marketing and financial forecasting. Information Processing \& Management, 57(5), Art. No. 102314.

5. Ford, J.B. (2019). What do we know about social-media marketing? Journal of Advertising Research, 59(4), 383-384.

6. Tafesse, W., Wien, A. (2018). Implementing social media marketing strategically: An empirical assessment. Journal of Marketing Management, 34(9-10), 732-749.

7. Mas-Tur, A., Tur-Porcar, A., Llorca, A. (2016). Social media marketing for adolescents: Social media marketing for adolescents. Psychology \& Marketing, 33(12), 1119-1125.

8. Jacobson, J., Gruzd, A., Hernández-García, Á. (2020). Social media marketing: Who is watching the watchers? Journal of Retailing and Consumer Services, 53, S0969698918307744.

9. South, J., Herscovitz, H. G., Bairner, A., Frost, C., Fitzgerald, P. (2011). Book reviews. Journalism Studies, 12(5), 705-712.

10. Drummond, C., O’Toole, T., McGrath, H. (2020). Digital engagement strategies and tactics in social media marketing. European Journal of Marketing, 54(6), 1247-1280.

11. Canovi, M., Pucciarelli, F. (2019). Social media marketing in wine tourism: Winery owners' perceptions. Journal of Travel \& Tourism Marketing, 36(6), 653-664.

12. Losekoot, M. (2019). \#Jak na site. Brno: Jan Melvil Publishing.

13. Asociácia digitálnych marketingových agentúr: Video marketing. (2017). E-book.

14. Hausman, A. (2012, July 5). 16 Differences Between Social Media and Traditional Media. Business2community. Retrieved from: https://www.business2community.com/ social-media/16-differences-between-social-media-and-traditional-media-0211995.

15. Chamberlain, L. (2016, March 31). GeoMarketing 101: What is Geotargeting? Geomarketing. Retrieved from: https:/geomarketing.com/geomarketing-101-what-isgeo-targeting.

16. Horný, J. (2012, November 19). Sú nové Facebook global pages naozaj to pravé pre vašu značku? Triad. Retrieved from: https://blog.triad.sk/zapisnik/su-nove-facebookglobal-pages-naozaj-to-prave-pre-vasu-znacku/. 